
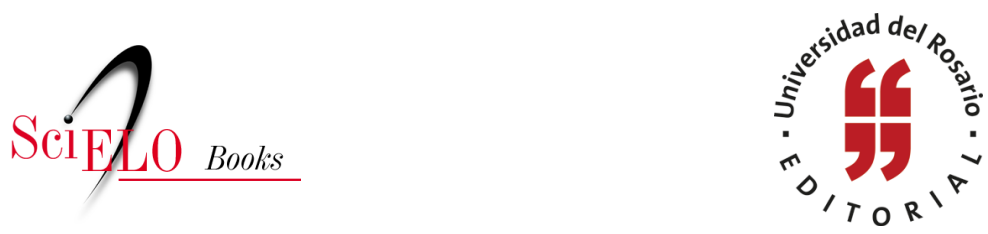

\title{
La cultura desde la extensión en la Universidad del Rosario
}

\author{
Dirección de Extensión
}

\section{SciELO Books / SciELO Livros / SciELO Libros}

\section{DIRECCIÓN DE EXTENSIÓN. VILLAMIZAR}

MALDONADO, R.E. La cultura desde la extensión en la Universidad del Rosario. In: DÍAZ TÁMARA, A., and GUZMÁN BEJARANO, M., eds. Proceso de construcción de la política cultural en la Universidad del Rosario [online]. Bogotá: Editorial Universidad del Rosario, Decanatura del Medio Universitario, 2014, pp. 79-86. ISBN: 978-958-738-541-0. https://doi.org/10.7476/9789587385410.0004.

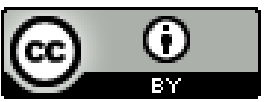

All the contents of this work, except where otherwise noted, is licensed under a Creative Commons Attribution 4.0 International license.

Todo o conteúdo deste trabalho, exceto quando houver ressalva, é publicado sob a licença Creative Commons Atribição 4.0.

Todo el contenido de esta obra, excepto donde se indique lo contrario, 


\section{La cultura desde la extensión en la Universidad del Rosario}

Dirección de Extensión

La Universidad del Rosario considera que una "formación integral cubre todos los aspectos de la persona humana, como ser racional y social, tanto en sus aspectos espirituales, culturales e intelectuales" (Universidad del Rosario, 2010), y es por ello que nuestra alma mater otorga un alto grado de importancia a la cultura como transformador social de las relaciones colectivas al interior de la Universidad para un desarrollo humano sostenible. Con esto permite un fuerte vínculo en la integración e interacción entre la Universidad y el entorno: "Las universidades en uso de su autonomía y su naturaleza, salvaguardan y recuperan la cultura y generan conocimiento en bien de las comunidades y la sociedad en general" (ASCUN, 2012, 12).

El reto de una formación integral que responda con un máximo sentido de responsabilidad, considera la persona formada en el saber, en el saber hacer pero en mayor relevancia en el ser, pues es desde allí donde sus motivaciones, representaciones, imaginarios, memorias y referentes deben ser superados para dar una lectura desde la realidad de la sociedad que le permita, como ser humano, abordar los retos que exige un entorno complejo y con amplia diversidad cultural, como es el caso de la sociedad colombiana. Todo esto le recuerda constantemente la importancia de su papel en la construcción activa de la sociedad.

Este tipo de procesos requiere de una articulación real entre las funciones sustantivas universitarias como la "docen- 
cia, la investigación y la extensión”, que permita discusiones y construcciones de nuevas realidades desde el ejercicio de la innovación y la creación en todos sus campos, pero también en el respeto a las tradiciones del saber plural. "Tal enfoque rompe los paradigmas sobre la cultura en la Universidad, que tiende a ligar lo cultural a eventos dirigidos a su comunidad interna, puesto que lo cultural no puede seguir reduciéndose a oficinas de eventos y espectáculos que solo propician espacios para la conformación de agrupaciones artísticas por parte de los estudiantes" (ASCUN, 2008, 23). El concepto de cultura está basado en un "fundamento de la nacionalidad" y como elemento clave para el diálogo social en el que "los programas y proyectos de gestión cultural constituyen formas de circulación, difusión y divulgación del conocimiento cultural, artístico, científico, técnico y tecnológico que tienen como propósito la formación integral de públicos amplios y heterogéneos, la apropiación de diversos temas y la participación y acceso a las diversas expresiones artísticas y culturales por parte de los públicos internos y las comunidades externas de las Universidades que garantizan presencia en la vida social y cultural del país" (ASCUN, 2008).

Bajo este enfoque, la Universidad del Rosario hoy puede presentar resultados concretos frente a los procesos de articulación entre sus funciones sustantivas y en la integración e interacción con las comunidades externas que representan un valioso conocimiento social que ha ampliado las posibilidades de la Universidad tanto en su interior como en la construcción y acompañamiento del fortalecimiento en temas culturales de interés y relevancia en el país durante los últimos años.

La especialización en Gestión Cultural de la Escuela de Ciencias Humanas es un ejemplo de ello. A través de procesos de formación e investigación y soportado en un diálogo con actores involucrados, se logra un contraste de lo que se produce 
en la Universidad con la realidad, lo cual ha permitido generar nuevas propuestas que han llevado a la Universidad del Rosario a ser referente en temas del sector cultural en Colombia y que han permitido desarrollar un trabajo conjunto con el Ministerio de Cultura en temas de capacitación y formación en diversos lugares de la geografía colombiana como San Andrés, Sincelejo, Quibdó, Aguachica, Yopal, Apartadó, Buenaventura, Villavicencio, Pitalito, Barrancabermeja, Cartago, Condoto, El Banco, Puerto Tejada, San José del Guaviare, Sibundoy y Villanueva, para un total de 441 participantes activos en procesos de capacitación de política cultural en el año 2010 y 527 en el 2011.

Así mismo, se desarrollaron procesos de formación a través de plataformas cien por ciento virtuales con el Ministerio de Relaciones Exteriores cuyo enfoque fue "la cultura como herramienta de política exterior". En dichos procesos, el $35 \%$ de los participantes pertenecían a embajadas de los países iberoamericanos, fortaleciendo así la importancia de la cultura en diferentes ámbitos del contexto y enriqueciendo la experiencia de intercambio de saberes durante el desarrollo de la capacitación.

Por iniciativa de la Escuela de Ciencias Humanas y con el apoyo de la Dirección de Extensión surgen las Ferias Locales de Cultura, un modelo de intervención de la Universidad con el entorno, bajo el concepto de valor compartido. Desde el año 2010 se implementa para las localidades de Candelaria, Barrios Unidos, Los Mártires y Usaquén, y sus objetivos son:

1. Promover la cultura y el fortalecimiento de la industria cultural de las localidades a través de la conformación de redes competitivas, empresariales y sociales, propendiendo por generar ingresos a las empresas 
culturales bajo el concepto de Responsabilidad Social Universitaria.

2. Generar oportunidades de negocio con una oferta de bienes y servicios que satisfaga las expectativas de posibles compradores.

3. Dinamizar sinergias e integrar esfuerzos de diferentes entidades en pro del desarrollo cultural con el fin de promover redes locales en Bogotá.

El modelo se basó en un trabajo de campo con actores sociales y en un fuerte esquema de gestión de alianzas con gestores culturales de las localidades, organizaciones culturales, instituciones universitarias, alcaldías, secretarías de Cultura, Secretaría de Desarrollo Económico, Instituto Distrital de Turismo, Gobernación de Cundinamarca, secretarías de Gobierno, Ministerio de Industria, Comercio y Turismo y Ministerio de Cultura. Se buscó crear un escenario que permitiera un encuentro entre la oferta de bienes y servicios culturales de las localidades, con la demanda del sector empresarial, tales como Cajas de Compensación, ARP, Fundaciones, Federaciones, sector hotelero, asociaciones, restaurantes y colegios.

Como resultado de este proceso se obtuvo una caracterización de oferta de bienes y servicios de la industria cultural así: Candelaria con 83 organizaciones culturales, Usaquén con 137, Barrios Unidos con 181 y Mártires con 389 organizaciones culturales clasificadas bajo los lineamientos de la política cultural distrital 2004-2016 en dimensiones artísticas como: formación, creación, investigación, danza, teatro, artes visuales, artes plásticas, literatura y circulación.

En una fase inicial se realizó la primera rueda de negocios durante el 28 y 29 de octubre de 2010 en la localidad de Usaquén y la segunda rueda durante el 25 y 26 de noviembre 
del mismo año en la localidad de La Candelaria. En ambas ocasiones se contó con expresiones artísticas cuya selección se realizó a través de convocatorias. Como resultado de esta primera feria se identificaron tres potenciales compradores y se cerró un negocio entre la compañía de títeres Baúl de Fantasía y Coomeva Recreación y Turismo, además de un volumen importante de contactos entre los asistentes con el fin generar trabajo conjunto.

En una fase posterior se migró a un modelo de ferias especializadas por componentes artísticos y se realizó así la primera Feria Local de Cultura de Arte Dramático, Danza y Música el 2 de septiembre de 2011, la cual contó con un showcase en el cual se mostraron apartes de las obras de las diferentes organizaciones participantes y se realizó una rueda de negocios. En esa ocasión se contó con la asistencia de siete organizaciones caracterizadas y vinculadas desde el año 2010 y con dos organizaciones nuevas con las cuales se realizaron alianzas como el Teatro R101 con instalaciones y personal para este evento, y la Fundación Arte Sin Fronteras con obras de niños y jóvenes con discapacidad cognitiva.

Como resultado de este ejercicio asistieron delegados de cooperativas, colegios y gestores culturales, los cuales manifestaron el interés de continuar con los escenarios de vinculación entre el empresariado y el sector cultural. Como potenciales negocios de esta jornada se pueden mencionar: Colegio San Carlos, Corporación Coomeva, Colegio Tilatá y clúster de turismo de La Candelaria.

En una segunda ocasión (el 2 de diciembre de 2011) se realizó la feria local de cultura especializada en componentes de artes plásticas en colaboración con la Fundación Artes Sin Fronteras y la Casa del Valle, la cual contó con una participación de un colectivo de joyeros, tres pintores independientes, un 
colectivo de pintores y un colectivo de diseñadores multimedia. Como resultado importante de esta jornada se destaca la necesidad de incentivar la generación de redes entre los artistas y la necesidad de destacar al sector de artes plásticas dentro del empresariado. Por ello se ha continuado con la gestión ante diversas instituciones para la participación de las organizaciones culturales locales en festivales especializados muy conocidos a nivel distrital y nacional.

Por otro lado, es importante destacar que la Universidad del Rosario ha sido protagonista y espectadora de la construcción de nuestro país, cuenta con grandes riquezas históricas que fortalecen las raíces colombianas culturales. Por ello, la Unidad de Patrimonio Histórico promueve la cultura desde la historia y permanentemente ofrece servicios a visitantes para acceder a documentos históricos de alta relevancia, realiza diversas actividades que promueven la riqueza histórica y patrimonial de la Universidad junto con la Decanatura de Medio Universitario mediante exposiciones que combinan lo artístico con lo histórico, como en la exposición Las huellas del Rosario en la Independencia en el marco de la celebración del bicentenario de la Independencia de Colombia. Es de resaltar que mediante este tipo de actividades la Universidad del Rosario abre sus puertas, su historia, su riqueza arquitectónica y su tradición a la sociedad colombiana.

\section{Algunos retos}

En la Universidad del Rosario consideramos que en una sociedad multicultural y diversa es necesario fortalecer actividades y líneas de investigación en aspectos culturales que permitan realizar contribuciones a la construcción de políticas públicas, así como encontrar mecanismos o alternativas que permitan potenciar de manera acelerada la riqueza cultural del país como 
fuentes generadoras de ingreso traducidas en la promoción de empresas culturales.

\section{Consideraciones puntuales}

- Es necesario promover la creación de grupos inter y multidisciplinarios que permitan generar fortalezas desde las diversas áreas del conocimiento.

- Es necesaria una mayor promoción para emprendimientos culturales entre los estudiantes y los egresados que haga que las expresiones artísticas y culturales pasen de ser consideradas solo como actividades de ocio a ser consideradas como alternativas de generación de ingreso permanente.

- Se requiere una mayor articulación interna en las diversas dependencias de la Universidad que intervienen en aspectos culturales, como Archivo Histórico, Decanatura del Medio Universitario, Escuela de Ciencias Humanas, Egresados y la Dirección de Extensión.

- La Universidad debe continuar con una intervención equilibrada en la sociedad que permita generar procesos de transformación social desde y a través de la cultura, por ello es necesario fortalecer el vínculo de la Universidad con su entorno, siendo este el Estado, el sector privado y las comunidades.

- Desde la Universidad es necesario buscar espacios culturales que conlleven la interacción con los diferentes actores de la sociedad y que permitan procesos de aprendizaje mutuo y promuevan nuevos proyectos.

Otros aspectos que consideramos pertinentes y adecuados frente a los retos que las Universidades debemos tener en cuenta son: 
- "Las relaciones docencia-investigación-cultura se enriquecen con las transformaciones curriculares, la formación integral, el diálogo de saberes y las preguntas que desde la cultura deben alimentar los procesos investigativos en cualquiera de las áreas del conocimiento" (ASCUN, 2007, 17).

- Se requieren escenarios que permitan un diálogo permanente, respetuoso y crítico entre la academia, los saberes especializados de la academia y los saberes y las experiencias culturales y sociales.

- "Es necesario fortalecer las relaciones cultura-educación-comunicaciones, entendida esta última como una construcción cultural de sentidos y no solo como una estrategia de carácter instrumental para apoyar las iniciativas institucionales" (ibid.).

- "Es necesario fortalecer las dinámicas de cooperación local, regional, nacional e internacional desde lo cultural" (ibid.).

- Uno de los mayores retos que tenemos como universidad es dotar de sentido a la sociedad a través de nuestra intervención en la formación de "recuperar el sentido de la vida digna, sin guerra, sin violencia, sin exclusión desde la diversidad cultural y la complejidad de la sociedad misma. Entendido este sentido como el conjunto complejo de representación, símbolos, conceptos y significados construidos históricamente" (ASCUN, 2007,13), siendo la cultura un vehículo importante de paz, respeto y de desarrollo para nuestra universidad y para el país. 